\title{
Fixation stability after surgical treatment of strabismus and biofeedback fixation training in amblyopic eyes
}

\author{
Otto Alexander Maneschg ${ }^{1,2^{*}}$, Mirella Telles Salgueiro Barboni ${ }^{1,2}$, Zoltán Zsolt Nagy ${ }^{1}$ and János Németh ${ }^{1,2}$
}

\begin{abstract}
Background: Visual fixation may be affected in amblyopic patients and, moreover, its stability may be associated with the effects of amblyopic treatments on visual performance in patients with strabismus. Therefore, fixation stability is a relevant biomarker that might predict the recurrence of amblyopia after a therapeutic intervention. Microperimetric biofeedback fixation training (BFT) can stabilize visual fixation in adult patients with central vision loss. It was the purpose of the present study to evaluate the effects of BFT on fixation stability in adult amblyopic patients after surgical intervention to treat strabismus.

Methods: Participants were 12 patients with strabismus (mean age $=29.6 \pm 8.5$ years; 6 females) and 12 healthy volunteers (mean age $=23.8 \pm 1.5$ years; 9 females). The protocol included ophthalmological and microperimetric follow-ups to measure fixation stability and macular sensitivity. BFT was applied monocularly to four amblyopic eyes either on the spontaneous preferential retinal locus or to a fixation area closer to the anatomical fovea after surgical treatment of strabismus.
\end{abstract}

Results: Baseline measurements showed significantly altered microperimetric average threshold in amblyopic eyes compared to fellow eyes $(p=0.024)$ and compared to control eyes $(p<0.001)$. Fixation was unstable in amblyopic eyes compared to control eyes $(p<0.001)$. Fixation stability did not significantly change after surgical alignment of strabismus ( $p=0.805$ ). BFT applied to operated eyes resulted in a more stable fixation with improvements of about $50 \%$ after three months of training.

Conclusions: Fixation stability improvements following BFT highlight its potential use in adult amblyopic eyes after the surgical alignment of the strabismus. Future investigations may also consider applying this method in combination with standard treatments to improve vision in amblyopic patients.

Keywords: Strabismus, Amblyopia, Microperimetry, Biofeedback fixation training, Squint surgery

\footnotetext{
* Correspondence: maneschg.otto@med.semmelweis-univ.hu;

ottomaneschg@gmail.com

${ }^{1}$ Department of Ophthalmology, Semmelweis University, Budapest, Hungary

${ }^{2}$ Bionic Innovation Center, Budapest, Hungary
} 


\section{Background}

Amblyopia is characterized by reduced visual acuity [1] associated with structural brain [2,3] and retinal [4] changes that are usually not observed during the standard ophthalmological examination. It occurs due to asymmetric interocular suppression of visual inputs to the cortex, very often caused by the misalignment (strabismus) of the eyes [5-7] and / or unequal and uncorrected refractive error (anisometropia) [8], and stimulus deprivation due to an obstruction of visual pathway $[7,9]$. In amblyopic adult eyes, cosmetic results are believed to be the main benefit for patients with chronic strabismus undergoing surgical treatment. Nevertheless, several studies have proved that binocular summation can be modulated after the alignment of the eyes [10, 11 ] and elimination of diplopia and/or a compensatory head posture [12-14]. However, the surgical alignment of the strabismic eyes in adult with amblyopia is usually not followed by visual acuity improvements. Moreover, it has been associated with risk of squint relapse [15].

Fixation stability is often affected in amblyopic patients [16]. It has been recently reported that visual acuity improvements are accompanied by changes in fixation stability after amblyopic treatment [17]. Therefore, fixational eye movements may be considered in amblyopic treatment. Microperimetry, or fundus-controlled visual field examination, is a relatively new method to measure monocular macular light sensitivity while recording eye movements to monitor visual fixation (for review see Rohrschneider et al., 2008) [18]. In addition, the continuous recording of eye movements during the examination enables the establishment of the preferred retinal locus (PRLs), which is the preferential location on which the tested eye fixates a central target. This approach allows recording and quantifying fixation stability [19].

The biofeedback fixation training (BFT), integrated in some microperimetric systems, allows selecting one retinal location to be stimulated for either providing a more stable fixation or to change PRL retinal location [20, 21]. It has been earlier reported [22, 23] and increasingly emphasized [24-27] that BFT improves fixation stability in patients with low vision. The conditions causing low vision due to retinal alterations in macular diseases may stimulate the replacement of the fixation area to a less affected surrounding area (eccentric viewing). In contrast, amblyopic patients with strabismus may display eccentric fixation, in which the visual center (functional fovea) is shifted to a non-foveal area due to suppressive mechanisms during the critical period of development [28]. It was long demonstrated that visual fixation can be improved with auditory feedback in amblyopia [29]. More recently, functional gain was demonstrated in children and adults undergoing visual training using pattern stimulation associated with auditory feedback [30, 31].
We hypothesize that BFT providing a better control of microsaccades could improve fixation stability in amblyopic adult eyes after surgical alignment of the strabismus. The purpose of the present study was to investigate the effects of surgical treatment and BFT on fixation stability.

\section{Methods \\ Patients}

The study was performed according to the tenets of the Declaration of Helsinki and was approved by the ethics committee of the National Healthcare Service Center (Egészségügyi Nyilvántartási és Képzési Központ, registration number ENKK 037871-006/2016/OTIG) and by the National Institute of Pharmacy and Nutrition (Országos Gyógyszerészeti és Élelmezés-egészségügyi Intézet, registration number OGYÉI/42821/2019). All participants were informed about the nature and possible consequences of the study giving their written consent to participate in the study.

Participants were 12 patients with strabismus (mean age $=29.6 \pm 8.5$ years; 6 females; 9 amblyopic) and 12 healthy volunteers (mean age $=23.8 \pm 1.5$ years; 9 females). Table 1 shows pre / postoperative clinical data from the patients recorded before the BFT. Patients 1 to 9 underwent surgical alignment of the strabismus, four of them underwent BFT after the surgery. Patients 10, 11 , and 12 were amblyopic with small angle strabismus under $5^{\circ}$ without surgical indication, but they were included in the baseline analysis of the microperimetric parameters and one follow-up after three months without any intervention (non-treated).

Inclusion criteria for all subjects were: absence of ophthalmological diseases (other than the diseases studied) and absence of neurological diseases or medications that could affect the central nervous system. Inclusion criteria for the group undergoing the training were surgical alignment of strabismus and amblyopia with decimal best-corrected distance visual acuity (BCDVA) of 0.5 in decimals (logMAR 0.3 ) or worse in the amblyopic eye. Moreover, subjects undergoing BFT had to agree of attending weekly training sessions and follow-up examinations in the eye clinic.

The study protocol included surgical alignment of the strabismus for patients with strabismic angle above $5^{\circ}$, follow-up examinations, and biofeedback fixation training (Fig. 1). For patients undergoing surgical alignment of the strabismus baseline and follow-up examinations were performed before and after surgery, respectively. Training subjects performed initial, mid-training, endtraining, and post-training final follow-ups. Patients not receiving any treatment performed the baseline examination and one follow-up examination within three months of interval. The healthy volunteers of the control group were tested twice within one week interval. 
Table 1 Clinical data of the patients

\begin{tabular}{|c|c|c|c|c|c|c|c|c|}
\hline \multirow[b]{2}{*}{$\mathbf{N}$} & \multirow[b]{2}{*}{ Etiology } & \multicolumn{2}{|l|}{ Refraction } & \multicolumn{2}{|c|}{ Preoperative BCDVA ${ }^{a}$} & \multirow{2}{*}{$\begin{array}{l}\text { Postoperative BCDVA } \\
\text { Treated eye }\end{array}$} & \multirow{2}{*}{$\begin{array}{l}\text { Surgical } \\
\text { alignment } \\
\text { of } \\
\text { strabismus }\end{array}$} & \multirow[t]{2}{*}{ BFT } \\
\hline & & Treated eye & Fellow eye & Treated eye & Fellow eye & & & \\
\hline 1 & S & plan $-0.50105^{\circ}$ & plan $-0.50146^{\circ}$ & 0.7 & 0.0 & 0.7 & Right & Right \\
\hline 2 & SA & $+3.00-4.5010^{\circ}$ & +0.50 & 1.5 & 0.0 & 1.4 & Left & Left \\
\hline 3 & SA & $+4.25-1.25175^{\circ}$ & $+0.50-1.00160^{\circ}$ & 1.4 & 0.0 & 1.4 & Right & Right \\
\hline 4 & SA & $+2.75-0.5020^{\circ}$ & $-0.50-1.00155^{\circ}$ & 0.3 & 0.0 & 0.3 & Right & Right \\
\hline 5 & S & plan & plan & 0.0 & 0.0 & 0.0 & left & - \\
\hline 6 & S & $+0.50-0.50180^{\circ}$ & $+1.00-0.50110^{\circ}$ & 0.1 & 0.1 & 0.1 & right & - \\
\hline 7 & S & $-0.25-0.5010^{\circ}$ & $+0.75-0.75165^{\circ}$ & 0.0 & 0.0 & 0.0 & left & - \\
\hline 8 & SA & $+1.25-2.7570^{\circ}$ & plan & 0.2 & 0.0 & 0.2 & Right & - \\
\hline 9 & SA & $+2.50-2.0090^{\circ}$ & plan & 0.1 & 0.0 & 0.1 & Right & - \\
\hline 10 & SA & $+3.50+0.50100^{\circ}$ & plan & 0.7 & 0.0 & - & - & - \\
\hline 11 & SA & +7.00 & plan & 0.7 & 0.0 & - & - & - \\
\hline 12 & SA & +2.25 & $+0.50-1.2590^{\circ}$ & 1.3 & 0.0 & - & - & - \\
\hline
\end{tabular}

$S$ strabismus; $S A$ strabismus and anisometropia; ${ }^{a} B C D V A$ best-corrected distance visual acuity (LogMAR) before biofeedback fixation training;

\section{Surgical alignment of the strabismus}

Strabismus surgery was performed under general anaesthesia. In case of recession the muscle was reattached backwards at a targeted distance from the original insertion, using standard dosage patterns depending on the preoperative deviation [32, 33]. If resection was necessary, the muscle was shortened accordingly the standard Parks surgical tables [34]. There were no intraoperative or postoperative complications.

\section{Clinical examinations}

All subjects underwent a comprehensive ophthalmological examination including best corrected distance visual acuity (BCDVA), measured with electronic visual acuity testing charts in LogMAR values which allowed reordering optotypes randomly at each stimulus presentation after correcting refractive errors with spectacles and always by the same examiner. Moreover, orthoptic examination to measure horizontal and vertical deviations by cover test was performed. Some subjects were tested with near stereoacuity Stereo Fly test (LEA Test Intl, LLC, Chicago, USA) with circles test range between 800 and 40 arc sec. Furthermore, the intraocular pressure (IOP) measurement and fundus examination after dilatation of the pupils were performed.

The Macular Integrity Assessment microperimeter (MAIA; CenterVue, Padova, Italy) was used to evaluate

\begin{tabular}{|c|c|c|c|c|}
\hline Surger & $\begin{array}{c}\text { Initial } \\
\text { ry } \\
\text { follow-up }\end{array}$ & $\begin{array}{l}\text { Mid-training } \\
\text { follow-up }\end{array}$ & $\begin{array}{l}\text { End-training } \\
\text { follow-up }\end{array}$ & $\begin{array}{l}\text { Final } \\
\text { follow-up }\end{array}$ \\
\hline Baseline [ & $\sim 1 \mathrm{mo}$ & Training period ( $\sim 6 \mathrm{mo})$ & No trair & \\
\hline
\end{tabular}

Fig. 1 Complete protocol applied to the subjects undergoing surgical alignment of strabismus plus biofeedback fixation training macular sensitivity with the Expert Protocol (37 macular points up to $5^{\circ}$ of eccentricity) using Goldmann standardized stimuli. The microperimeter is equipped with a scanning laser ophthalmoscope with real-time eye tracking system providing information about the fixation along the test. The patient's task was, as in the conventional perimeters, to press a button in order to indicate the presence of a light spot whenever it was detected. The exported parameters, average threshold (average sensitivity of the macular points tested) and fixation stability were compared. Fixation stability is given as the bivariate contour ellipse area (BCEA) for 63 and 95\% of the fixation positions and the frequency of fixation points (\%) of the recorded points) within $1^{\circ}(\mathrm{P} 1)$ and $2^{\circ}$ (P2) of visual angle. Previous reports have shown details regarding the methods $[18,35]$ and the microperimetric parameters $[19,20]$.

\section{Biofeedback fixation training}

Based on previous reports [29, 30], biofeedback fixation training was performed monocularly to the amblyopic eye once per week for six months (with a mid-training follow-up examination) without interval. The biofeedback fixation training was identically delivered to all patients. Only the selection of the training retinal locus differed among the patients. The spontaneous preferred retinal locus (PRL) was selected as the training retinal locus for patients 1 and 4 with central fixation while the training retinal locus was another point near to the anatomical fovea (temporally shifted related to the original fixation area) for patients 2 and 3 with eccentric fixation, determined using high resolution OCT (SPECTRALIS system, Heidelberg. Engineering, Heidelberg, Germany). 
During the training, the patient was requested to look at $1^{\circ}$ white fixation spot monocularly (only the amblyopic eye) in a dark room. The examiner continuously guided the patient to inform him where to look while an auditory feedback beep increased its frequency as the patient approached fixation target by slowly moving the eyes. To guide the patient where to look, the words right, left, up, and down were used. Every time when the position of the eye reached exactly the desired fixation point, an auditory stimulus (Sonata Mozart) was delivered, indicating the correct position of the eye. The patient kept the fixation at the position as much as possible. Fixation stability was measured in all training sessions. Only patients participating to all training sessions and completing the six months period of training plus middle and final follow-up examinations were included in the study.

\section{Statistics}

The data analyzed are shown in the supplemental material. Group differences were evaluated using the nonparametric Mann-Whitney test (SPSS, Statistical Package for the Social Sciences, Hong Kong, China) $p$-values were corrected for multiple (six) comparisons. $p$ values $<0.05$ were considered statistically significant. Since only a small number of patients completed all protocol phases, we were careful with the statistical analysis for the paired comparisons. We described some results without drawing a statistical conclusion.

\section{Results}

Baseline macular sensitivity and variation of fixation stability Baseline microperimetric parameters from nine amblyopic patients included in the study (subjects 1 to 4 and 8 to 12 in Table 1) and the healthy controls are shown in Fig. 2 for amblyopic (red; $N=9$ ), fellow (blue; $N=9$ ), and control (black; $N=24$ ) eyes. As expected, macular thresholds (Fig. 2A) were significantly altered in the amblyopic eyes compared to both fellow $(p=0.024)$ and control $(p<0.001)$ eyes, but they were comparable in the fellow and control eyes $(p=0.290)$.

Fixation stability (Fig. 2B and C) expressed as BCEA $\left(\operatorname{logdeg}^{2}\right) 63$ and 95\% index, respectively, was also significantly altered in amblyopic patients. A significantly increased BCEA in amblyopic eyes compared to control eyes $(\mathrm{p}<0.001)$ was observed. Fixation stability was intermediate in the fellow eyes of the amblyopic patients as it showed statistically non-significant marginal difference $(p=0.066$ and $p=0.084)$ compared to controls, however, statistically similar to amblyopic eyes (Bonferroni corrected $p=0.113$ ).

We previously showed that fixation stability may improve after repeated microperimetric examination in patients with low vision due to age-related macular degeneration [36]. To check the variability of fixation stability in amblyopic and fellow eyes, a second examination was carried out in five amblyopic patients (subjects 3 and 4) before the training, and non-trained subjects 10, 11, and 12 in Table 1) three months after the baseline examination without interventions. Figure $3 \mathrm{~A}$ and $\mathrm{B}$
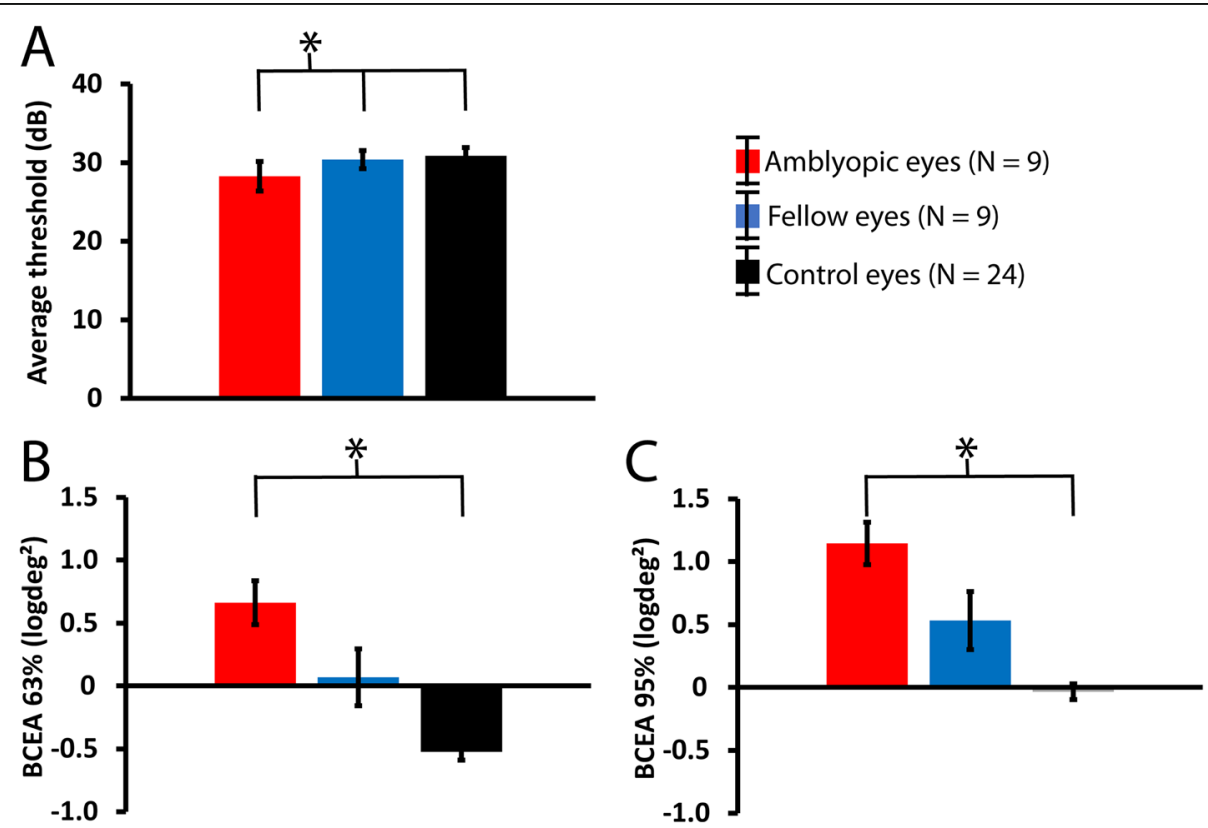

Fig. 2 Mean ( \pm one standard error of the mean) baseline microperimetric parameters. A: average thresholds (in dB), B: BCEA 63\%, and C: BCEA 95\% (logdeg 2 ) for amblyopic (red; $N=9$ eyes), fellow (blue; $N=9$ eyes), and control (black; $N=24$ eyes of 12 participants) eyes. All amblyopic patients ( 1 to 4 and 8 to 12 in Table 1$)$ were included. Significant $(p<0.05)$ differences are marked with an asterisk 

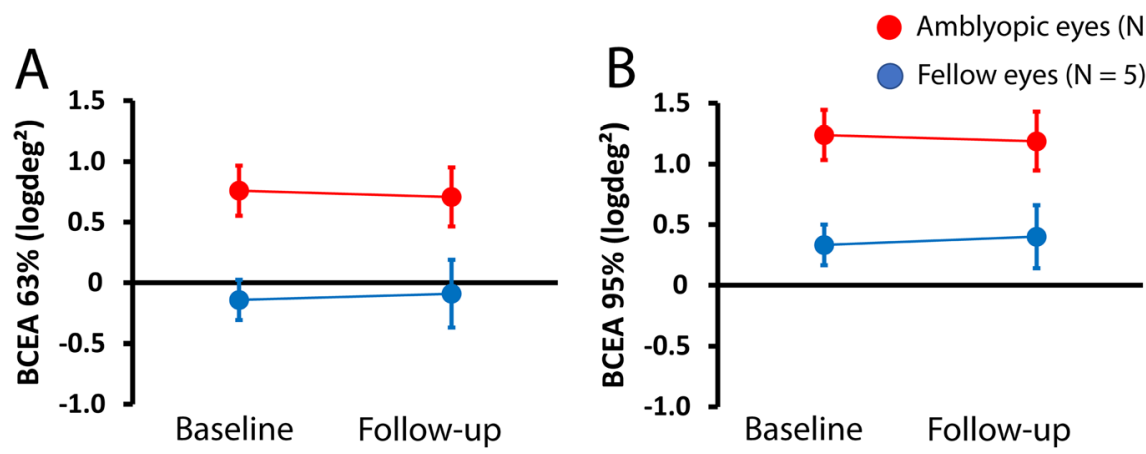

Fig. 3 Mean ( \pm one standard error of the mean) fixation stability obtained at the baseline examination and at the 3-month follow-up examination with no intervention between the two examinations. Amblyopic (red; $N=5$ ) and fellow (blue; $N=5)$ eyes for BCEA 63\% (A) and BCEA 95\% (B) in logdeg ${ }^{2}$

show average fixation stability values of BCEA (63 and $95 \%$, respectively) obtained during the baseline examination and the 3-month follow-up examination for amblyopic (red; $N=5$ ) and fellow (blue, $\mathrm{N}=5$ ) eyes. Both fixation parameters, BCEA63\% and BCEA95\%, were relatively stable after three months.

\section{Effects of the surgery and surgery + BFT}

Examinations were performed before and about one month after the surgical alignment of the strabismus.
Figure 4 (1st column) shows mean ( \pm one standard error of the mean) of the microperimetric parameters before and after the surgery (red symbols) and control values (black symbols) obtained twice within one week interval. Average thresholds and fixation parameters, BCEA 63\% and BCEA 95\% displayed slightly changed values. Mean average threshold was $29.7 \pm 0.8(\mathrm{~dB})$ before and $30.6 \pm$ $0.3 \mathrm{~dB}$ after the surgery (Fig. 4A). The mean difference between the baseline and the follow-up examination was 0.9 $\mathrm{dB}$, above the expected control variation that was $0.3 \mathrm{~dB}$.

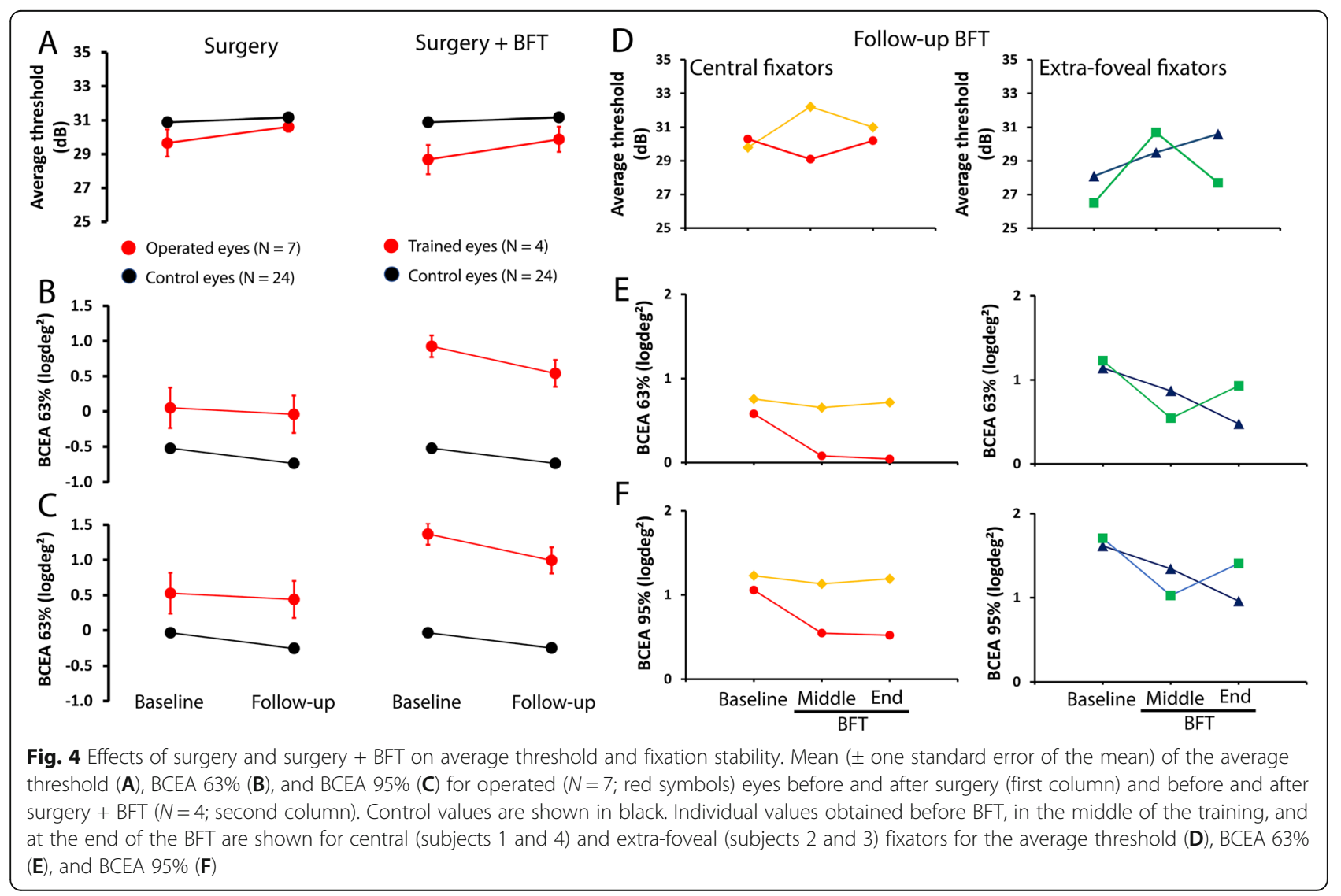


Fixation stability improved slightly after surgery. Before the surgery, the means were $0.05 \pm 0.3\left(\operatorname{logdeg}^{2}\right)$ and $0.53 \pm 0.3\left(\operatorname{logdeg}^{2}\right)$ for BCEA 63\% and BCEA 95\%, respectively. After the surgery, they were $-0.04 \pm 0.3$ $\left(\operatorname{logdeg}{ }^{2}\right)$ and $0.44 \pm 0.3\left(\operatorname{logdeg}{ }^{2}\right)$ for BCEA $63 \%$ and BCEA 95\%, respectively. However, the changes observed before (baseline) and after (follow-up) the surgery were not statistically significant (average threshold: $p=0.620$ and fixation stability: $p=0.805$.

Four patients (Patients 1 to 4 in Table 1) underwent BFT applied monocularly to the operated (amblyopic) eye during approximately six months. Figure 4 (2nd column) shows mean ( \pm one standard error of the mean) of the microperimetric parameters before and after the surgery + BFT (red symbols) and control values (black symbols) obtained twice within one week interval. Slight increase of the mean average threshold (Fig. 4A) after surgery + BFT (average threshold before $28.7 \pm 0.8$ and after $29.9 \pm 0.7 \mathrm{~dB}$ ) was observed. Moreover, a prominent improvement in fixation stability was found. BCEA values (Figs. $4 \mathrm{~B}$ and $\mathrm{C}$ ) decreased (BCEA63\% before $0.93 \pm 0.2$ and after $0.54 \pm 0.2 \operatorname{logdeg}^{2}$ and BCEA95\% before $1.40 \pm 0.2$ and after $1.02 \pm 0.2 \operatorname{logdeg}^{2}$ ) at about half of the postoperative values after BFT. Figure $4 \mathrm{D}$ shows average threshold changes during BFT for the central fixators (subjects 1 and 4) and extra-foveal fixators (subjects 2 and 3). We observed that extra-foveal fixators were likely to drive the mean average threshold increase displayed in the mean plots (Fig. 4A), as the central fixators showed relatively similar average threshold before and after BFT. Interestingly, fixation stability (Figs. 4E e
4F) improved (decreased BCEA values) for all four subjects undergoing BFT.

Figure 5 shows fixation stability $(\mathrm{P} 1=$ red circles and P2 = blue circles) recorded during the training sessions and BCDVAs (open triangles) examined during the training period for each of the four patients undergoing BFT. Observe that $y$-axes of the visual acuity (left; shown in Snellen decimal here) are in the same range in Fig. 5A and $\mathrm{B}$ and in Fig. $5 \mathrm{C}$ and $\mathrm{D}$ to better show changes among the training sessions. BFT has been interrupted earlier in one of the subjects (Fig. 5D) since 100\% fixation stability was achieved with 1.0 BCDVA.

The two subjects with central fixation, for whom spontaneous PRL was selected as the training point (Fig. 5C and D), more easily succeed in finding and keeping the eye position at the desired fixation point compared to the two extra-foveal fixators (Fig. 5A and B), for whom fixation points have been replaced. Accordingly, the central fixators achieved more stable fixation $(\mathrm{P} 2=100 \%$ in Fig. 5C and P1 / P2 $=100 \%$ in Fig. 5D) what was not observed in the extra-foveal trained subjects. Along BFT and follow-up examinations there was no strabismus relapse or worsening of the postoperative angle stability.

\section{Discussion}

The results of our present study show that: i) fixation stability is impaired in strabismic amblyopic adult eyes and ii) biofeedback fixation training (BFT) after alignment of the strabismus may improve fixation stability. Normal vision and appropriate binocular function depend upon the integrity of the eye's movements to
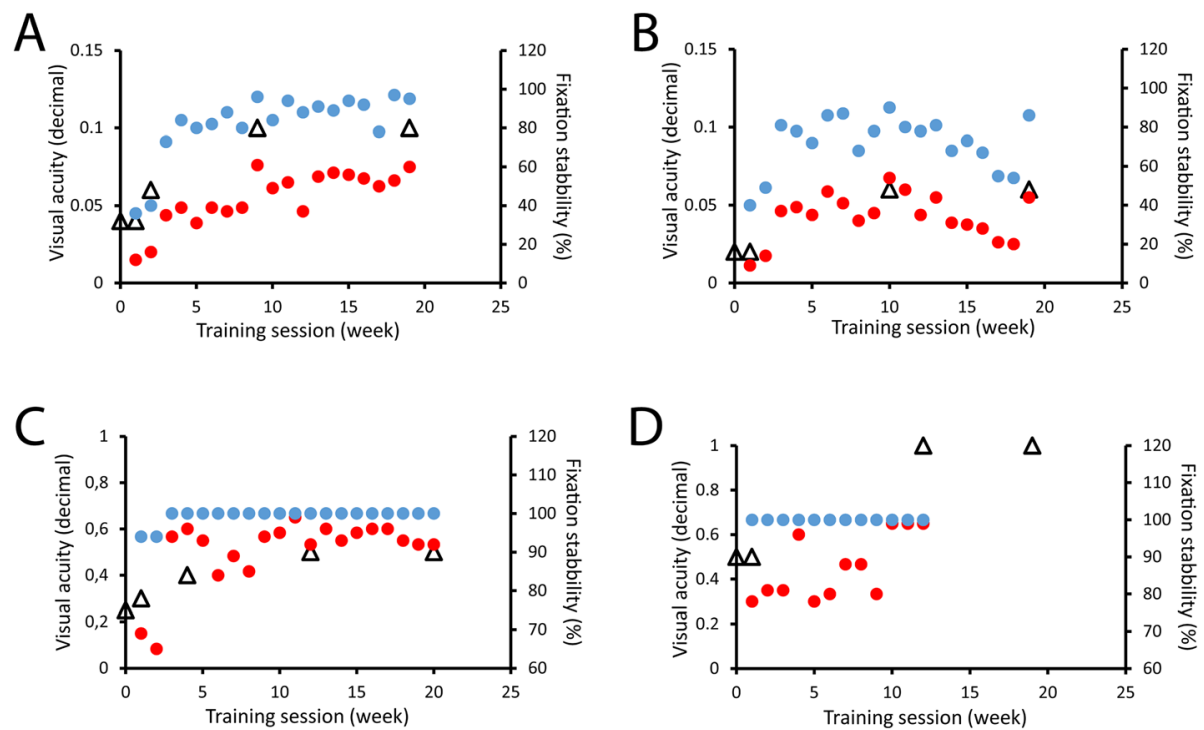

Fig. 5 Biofeedback fixation training of four patients undergoing surgical alignment of the strabismus (Patients $1=C, 2=A, 3=B$, and $4=D$ in Table 1). Fixation stability $(\mathrm{P} 1=$ red symbols and $\mathrm{P} 2=$ blue symbols) recorded during each training session. $\mathrm{BCDVA}$ (open triangles) examined during the training period for each of the four trained patients. $y$-axes at the left show BCDVA and at the right fixation stability. Fixation stability improved for all subjects. The training was interrupted earlier in one of the subjects (D) since 100\% fixation stability was achieved with 1.0 BCDVA 
efficiently guide both eyes so that visual target is brought and maintained at the fixational (foveal) area (for review see Collewijn \& Kowler, 2008) [37]. Accordingly, disturbed fixational eye movements may affect the quality of vision in subjects with strabismus and/or amblyopia $[16,38-42]$.

Fixational eye movements are characterized by slow oscillations of the eyes controlled by subcortical and cortical areas of the brain (for review see Kowler, 2011) [43]. The proper oculomotor control of the eyes ensures that the visual target is centrally placed on the fovea which is responsible for the best visual acuity that can be achieved by the visual system [44]. The present data emphasized $[16,38,45,46]$ that fixation in healthy eyes is quite stable while it is altered in patients with strabismus.

In subjects with normal vision, steady fixation allows keeping the visual target on the correct retinal position in both eyes so that visual attention is maintained until the object of interest can be detected or discriminated [47]. In contrast, unstable fixational eye movements continuously move the visual target out from the fixational locus, disturbing the attentional dedication to the visual target [39]. Here we show that fixation can be modulated in adult strabismic patients. We hypothesize that a more stable fixation could perhaps modulate monocular visual acuity and binocular vision in amblyopic eyes. Future investigations may address this question.

Amblyopia caused by strabismus, associated or not to anisometropia, may show eccentric and unstable fixation due to more severe extraocular motor alterations [40]. Previous reports taken together with the present data allow speculating that efforts to improve visual acuity of strabismic adult eyes with amblyopia should consider improving fixation stability in addition to stimulating visual perception of the amblyopic eye.

Although surgical correction of eye's position in infants may successfully result in normal visual development during the critical period, reestablishment of fixation stability is not always achieved [16, 48]. In nonhuman adult primates, only a temporary improvement of fixation stability is observed after surgical treatment of strabismus [49]. Strabismus surgery delivered to the adult amblyopic eye is usually indicated as cosmetic correction, since visual perception and binocular vision are not expected to be changed after the surgical alignment. Functional improvements associated with surgical alignment of strabismus in adults are not clearly established. Some authors found that strabismus surgery significantly improves the self-reported quality of life due to a positive effect in visual performance [50,51]. Pineles et al. found that binocular summation is improved after strabismus surgery [11]. However other authors showed that binocular function are not significantly modulated by the surgical alignment of the eyes when the critical period of development is over [52].

We hypothesize that improvements in fixation stability after correction of the eye position and BFT, may stimulate visual mechanisms responsible for the spatial vision in amblyopic eyes, increasing the possibility of visual acuity improvement. Among several types of behavioural rehabilitation for amblyopia [53-55], improvement of visual function provided by a short-term biofeedback training delivered to anisometropic amblyopic eyes of teenagers has been reported [30]. Here we reported that strabismic amblyopic eyes may benefit from BFT after surgical alignment of strabismus. Further studies with a large population may investigate the relations between clinical parameters, such as binocular balance [56], and visual improvements provided by BFT. In addition, to establish the proper criteria for selecting those patients who would more likely benefit from BFT for enhancing visual performance in amblyopic eyes.

Limitations of our study are the small sample size of participants. Further investigation with a larger population is necessary to confirm the present results. Moreover, although our results showed that surgical correction alone was not capable to improve fixation stability, a case-control study, in which some subjects are not enrolled in the training program and some subjects performing sham training after the surgical correction, would allow us to evaluate if the fixational improvements demonstrated here would be expected after surgical correction of strabismus or if they are related to the microperimetric biofeedback fixation training. Finally, we spculate that a more stable fixation of an amblyopic eye would help maintaining the primary position of the eye which could, in turn, reduce the possibility of strabismus relapse after the surgical correction.

\section{Conclusions}

Biofeedback fixation training is a non-invasive, painless method and simple-to-perform therapeutic option for stabilizing fixation and improving visual function in several diseases affecting the central vision [22, 57]. It has been extensively reported to improve residual vision in patients with age-related macular degeneration and several other retinal conditions [58-61]. We hope the present report highlights the beneficial use of BFT as a therapeutic option to improve fixation stability in amblyopic eyes after surgical strabismus correction. Alternatively, this rehabilitation method could be associated with the standardized treatments as addictive therapy to improve visual function in adult amblyopic eyes as an attempt to enhance its effect. 


\section{Supplementary Information}

The online version contains supplementary material available at https://doi. org/10.1186/s12886-021-02020-3.

\section{Additional file 1.}

\section{Acknowledgments}

We would like to thank very much the volunteers who kindly consented to participate in this study.

\section{Authors' contributions}

OAM made substantial contributions to conception and design, or acquisition of data, or analysis and interpretation of data. MTSB made substantial contributions to conception and design, or acquisition of data, or analysis and interpretation of data. ZZN has been involved in drafting the manuscript or revising it critically for important intellectual content; given final approval of the version to be published. JN made substantial contributions to conception and design, or acquisition of data, or analysis and interpretation of data and has been involved in drafting the manuscript or revising it critically for important intellectual content; given final approval of the version to be published.

\section{Funding}

National Research, Development, and Innovation Fund of Hungary, financed under the National Bionics Program funding scheme (Project no. ED_17-12017-0009) to JN and the Postdoctoral excellence program scholarship OTKA (Project no. PD134799) to MTSB.

\section{Availability of data and materials}

The datasets generated and/or analysed during the current study are available in a supplementary excel file attached to the submission.

\section{Declarations}

\section{Ethics approval and consent to participate}

The study design followed the tenets of the Declaration of Helsinki for biomedical research in human subjects, and the procedures were approved by the ethics committee of the National Healthcare Service Center (Egészségügyi Nyilvántartási és Képzési Központ, registration number ENKK 037871-006/2016/OTIG) and by the National Institute of Pharmacy and Nutrition (Országos Gyógyszerészeti és Élelmezés-egészségügyi Intézet, registration number OGYÉl/42821/2019). Since this was a prospective study, written informed consent was required. Written informed consent was obtained from each participant before they were included in the study, if the patient was minor (considered under the age of 16 years), the written consent to participate was obtained from the parents/guardians of the minors included in this study.

\section{Consent for publication}

Not applicable.

\section{Competing interests}

The authors declare that they have no competing interests.

Received: 19 January 2021 Accepted: 1 June 2021

Published online: 24 June 2021

\section{References}

1. Wallace DK, Repka MX, Lee KA, Melia M, Christiansen SP, Morse CL, et al. Amblyopia preferred practice pattern ${ }^{\oplus}$. Ophthalmology. 2018 Jan 1;125(1): P105-42. https://doi.org/10.1016/j.ophtha.2017.10.008.

2. Barrett BT, Bradley A, McGraw PV. Understanding the neural basis of amblyopia. Neurosci Rev J Bringing Neurobiol Neurol Psychiatry. 2004;10(2): 106-17.

3. Hess RF. Amblyopia: site unseen. Clin Exp Optom. 2001 Nov;84(6):321-36. https://doi.org/10.1111/j.1444-0938.2001.tb06604.x.

4. Szigeti A, Tátrai E, Szamosi A, Vargha P, Nagy ZZ, Németh J, et al. A morphological study of retinal changes in unilateral amblyopia using optical coherence tomography image segmentation. PLoS One. 2014;9(2):e88363. https://doi.org/10.1371/journal.pone.0088363.
5. Attebo K, Mitchell P, Cumming R, Smith W, Jolly N, Sparkes R. Prevalence and causes of amblyopia in an adult population. Ophthalmology. 1998 Jan; 105(1):154-9. https://doi.org/10.1016/50161-6420(98)91862-0.

6. Crawford ML, von Noorden GK. The effects of short-term experimental strabismus on the visual system in Macaca mulatta. Invest Ophthalmol Vis Sci. 1979 May;18(5):496-505.

7. von Noorden GK, Crawford ML. The sensitive period. Trans Ophthalmol Soc U K. 1979;99(3):442-6.

8. Barrett BT, Bradley A, Candy TR. The relationship between anisometropia and amblyopia. Prog Retin Eye Res. 2013 Sep;36:120-58. https://doi.org/10.1 016/j.preteyeres.2013.05.001.

9. Antonio-Santos A, Vedula SS, Hatt SR, Powell C. Occlusion for stimulus deprivation amblyopia. Cochrane Database Syst Rev. 2020;3:CD005136

10. Chang MY, Demer JL, Isenberg SJ, Velez FG, Pineles SL. Decreased binocular summation in Strabismic Amblyopes and effect of strabismus surgery. Strabismus. 2017;25(2):73-80. https://doi.org/10.1080/09273972.2017.1318153.

11. Pineles SL, Demer JL, Isenberg SJ, Birch EE, Velez FG. Improvement in binocular summation after strabismus surgery. JAMA Ophthalmol. 2015 Mar; 133(3):326-32. https://doi.org/10.1001/jamaophthalmol.2014.5265.

12. Kushner BJ, Morton GV. Postoperative binocularity in adults with longstanding strabismus. Ophthalmology. 1992 Mar;99(3):316-9. https://doi. org/10.1016/S0161-6420(92)31970-0.

13. Morris RJ, Scott WE, Dickey CF. Fusion after surgical alignment of longstanding strabismus in adults. Ophthalmology. 1993 Jan;100(1):135-8. https://doi.org/10.1016/S0161-6420(93)31703-3.

14. Murray ADN, Orpen J, Calcutt C. Changes in the functional binocular status of older children and adults with previously untreated infantile esotropia following late surgical realignment. J AAPOS Off Publ Am Assoc Pediatr Ophthalmol Strabismus. 2007 Apr;11(2):125-30. https://doi.org/10.1016/j.jaa pos.2006.10.016

15. Repka MX, Lum F, Burugapalli B. Strabismus, strabismus surgery, and reoperation rate in the United States: analysis from the IRIS registry. Ophthalmology. 2018;125(10):1646-53. https://doi.org/10.1016/j.ophtha.2018. 04.024 .

16. Subramanian V, Jost RM, Birch EE. A quantitative study of fixation stability in amblyopia. Invest Ophthalmol Vis Sci. 2013 Mar 19;54(3):1998-2003. https:// doi.org/10.1167/iovs.12-11054.

17. Aizenman A, Levi D. Eye on the prize: Fixational stability as a metric for the recovery of visual acuity in amblyopia. J Vis. 2020 Oct 20;20(11):558. https:// doi.org/10.1167/jov.20.11.558.

18. Rohrschneider K, Bültmann S, Springer C. Use of fundus perimetry (microperimetry) to quantify macular sensitivity. Prog Retin Eye Res. 2008 Sep;27(5):536-48. https://doi.org/10.1016/j.preteyeres.2008.07.003.

19. Molina-Martín A, Pérez-Cambrodí RJ, Piñero DP. Current clinical application of Microperimetry: a review. Semin Ophthalmol. 2018;33(5):620-8. https:// doi.org/10.1080/08820538.2017.1375125.

20. Markowitz SN, Reyes SV. Microperimetry and clinical practice: an evidencebased review. Can J Ophthalmol J Can Ophtalmol. 2013 Oct; 48(5):350-7. https://doi.org/10.1016/j.jcjo.2012.03.004.

21. Morales MU, Saker S, Wilde C, Rubinstein M, Limoli P, Amoaku WM. Biofeedback fixation training method for improving eccentric vision in patients with loss of foveal function secondary to different maculopathies. Int Ophthalmol. 2020 Feb;40(2):305-12. https://doi.org/10.1007/s10792-01901180-y.

22. Tarita-Nistor L, González EG, Markowitz SN, Steinbach MJ. Plasticity of fixation in patients with central vision loss. Vis Neurosci. 2009 Nov;26(5-6): 487-94. https://doi.org/10.1017/S0952523809990265.

23. Vingolo EM, Cavarretta S, Domanico D, Parisi F, Malagola R. Microperimetric biofeedback in AMD patients. Appl Psychophysiol Biofeedback. 2007 Dec; 32(3-4):185-9. https://doi.org/10.1007/s10484-007-9038-6.

24. Daibert-Nido M, Patino B, Markowitz M, Markowitz SN. Rehabilitation with biofeedback training in age-related macular degeneration for improving distance vision. Can J Ophthalmol J Can Ophtalmol. 2019;54(3):328-34. https://doi.org/10.1016/j.jcjo.2018.10.016.

25. Vingolo EM, Napolitano G, Fragiotta S. Microperimetric biofeedback training: fundamentals, strategies and perspectives. Front Biosci Sch Ed. 2018;10:48-64.

26. Melillo P, Prinster A, lorio VD, Olivo G, D'Alterio FM, Cocozza S, et al. Biofeedback rehabilitation and visual cortex response in Stargardt's disease: a randomized controlled trial. Transl Vis Sci Technol. 2020;9(6):6-6. https:// doi.org/10.1167/tvst.9.6.6. 
27. Barboni MTS, Récsán Z, Szepessy Z, Ecsedy M, Nagy BV, Ventura DF, et al. Preliminary findings on the optimization of visual performance in patients with age-related macular degeneration using biofeedback training. Appl Psychophysiol Biofeedback. 2019 Mar;44(1):61-70. https://doi.org/10.1007/s1 0484-018-9423-3.

28. Siepmann K, Reinhard J, Herzau V. The locus of fixation in strabismic amblyopia changes with increasing effort of recognition as assessed by scanning laser ophthalmoscope. Acta Ophthalmol Scand. 2006;84(1):124-9.

29. Flom MC, Kirschen DG, Bedell HE. Control of unsteady, eccentric fixation in amblyopic eyes by auditory feedback of eye position. Invest Ophthalmol Vis Sci. 1980 Nov;19(11):1371-81.

30. Esposito Veneruso P, Ziccardi L, Magli G, Falsini B, Magli A. Short-term effects of vision trainer rehabilitation in patients affected by anisometropic amblyopia: electrofunctional evaluation. Doc Ophthalmol Adv Ophthalmol. 2014;129(3):177-89. https://doi.org/10.1007/s10633-014-9462-x.

31. Lapajne $L$, Roškar S, Tekavčič Pompe M, Svetina M, Jarc-Vidmar M, Hawlina M. Vision training with VEP biofeedback in amblyopia after the critical period. Doc Ophthalmol Adv Ophthalmol. 2020;141(3):269-78. https://doi. org/10.1007/s10633-020-09774-z.

32. von Noorden GK, Campos EC. Binocular Vision and Ocular Motility: Theory and Management of Strabismus. 6th ed. St. Louis: Mosby Edition; 2001. p. $571-573$.

33. Rosenbaum AL, Santiago AP. Clinical strabismus management principles and surgical techniques. Philadelphia: WB Saunders Company; 2001. p. 553.

34. Parks MM. Atlas of strabismus surgery. Philadelphia: Harper and Row Publishing; 1983.

35. Acton JH, Greenstein VC. Fundus-driven perimetry (microperimetry) compared to conventional static automated perimetry: similarities, differences, and clinical applications. Can J Ophthalmol J Can Ophtalmol. 2013;48(5):358-63. https://doi.org/10.1016/j.jcjo.2013.03.021.

36. Szepessy Z, Barboni MTS, Nagy ZZ, Németh J. Retinal sensitivity and fixation stability changes during repeated Microperimetry. J Clin Exp Ophthalmol. 2017;8(6):1-7.

37. Collewijn $\mathrm{H}$, Kowler $\mathrm{E}$. The significance of microsaccades for vision and oculomotor control. J Vis. 2008;8(14):20.1-21.

38. Chung STL, Kumar G, Li RW, Levi DM. Characteristics of fixational eye movements in amblyopia: limitations on fixation stability and acuity? Vision Res. 2015;114:87-99.

39. Kowler $\mathrm{E}$, Anderson $\mathrm{E}$, Dosher $\mathrm{B}$, Blaser $\mathrm{E}$. The role of attention in the programming of saccades. Vis Res. 1995 Jul;35(13):1897-916. https://doi. org/10.1016/0042-6989(94)00279-U.

40. Schor C, Hallmark W. Slow control of eye position in strabismic amblyopia. Invest Ophthalmol Vis Sci. 1978 Jun;17(6):577-81.

41. Von Noorden GK, Mackensen G. Phenomenology of eccentric fixation. Am J Ophthalmol. 1962 Apr;53(4):642-60. https://doi.org/10.1016/0002-9394(62)91 987-6.

42. Zhang B, Stevenson SS, Cheng H, Laron M, Kumar G, Tong J, et al. Effects of fixation instability on multifocal VEP (mfVEP) responses in amblyopes. J Vis. 2008 Mar 19:8(3):16.1-14. https://doi.org/10.1167/8.3.16

43. Kowler E. Eye movements: the past 25 years. Vis Res. 2011 Jul 1:51(13):145783. https://doi.org/10.1016/j.visres.2010.12.014.

44. Putnam NM, Hofer HJ, Doble N, Chen L, Carroll J, Williams DR. The locus of fixation and the foveal cone mosaic. J Vis. 2005 Aug 17;5(7):632-9. https:// doi.org/10.1167/5.7.3.

45. González EG, Wong AMF, Niechwiej-Szwedo E, Tarita-Nistor L, Steinbach MJ. Eye position stability in amblyopia and in normal binocular vision. Invest Ophthalmol Vis Sci. 2012 Aug 9;53(9):5386-94. https://doi.org/10.1167/ iovs.12-9941.

46. Koylu MT, Ozge G, Kucukevcilioglu M, Mutlu FM, Ceylan OM, Akıncıoglu D, et al. Fixation characteristics of severe amblyopia subtypes: which one is worse? Semin Ophthalmol. 2017;32(5):553-8. https://doi.org/10.3109/0882 0538.2015.1123739.

47. McKee SP, Levi DM, Schor CM, Movshon JA. Saccadic latency in amblyopia. J Vis. 2016;16(5):3. https://doi.org/10.1167/16.5.3.

48. Hertle RW, Felius J, Yang D, Kaufman M. Eye muscle surgery for infantile nystagmus syndrome in the first two years of life. Clin Ophthalmol Auck NZ. 2009:3:615-24.

49. Pullela M, Degler BA, Coats DK, Das VE. Longitudinal evaluation of eye misalignment and eye movements following surgical correction of strabismus in monkeys. Invest Ophthalmol Vis Sci. 2016 Nov 1;57(14):6040-7. https://doi.org/10.1167/iovs.16-20481.

50. Koc F, Erten Y, Yurdakul NS. Does restoration of binocular vision make any difference in the quality of life in adult strabismus. Br J Ophthalmol. 2013 Nov;97(11):1425-30. https://doi.org/10.1136/bjophthalmol-2013-303704.

51. Glasman P, Cheeseman R, Wong V, Young J, Durnian JM. Improvement in patients' quality-of-life following strabismus surgery: evaluation of postoperative outcomes using the adult strabismus 20 (AS-20) score. Eye Lond Engl. 2013;27(11):1249-53.

52. Zhou J, Wang Y, Feng L, Wang J, Hess RF. Straightening the eyes Doesn't rebalance the brain. Front Hum Neurosci. 2017;11:453. https://doi.org/10.33 89/fnhum.2017.00453.

53. Papageorgiou E, Asproudis I, Maconachie G, Tsironi EE, Gottlob I. The treatment of amblyopia: current practice and emerging trends. Graefes Arch Clin Exp Ophthalmol Albrecht Von Graefes Arch Klin Exp Ophthalmol. 2019; 257(6):1061-78. https://doi.org/10.1007/s00417-019-04254-w.

54. Tsirlin I, Colpa L, Goltz HC, Wong AMF. Behavioral training as new treatment for adult amblyopia: a meta-analysis and systematic review. Invest Ophthalmol Vis Sci. 2015 Jun;56(6):4061-75. https://doi.org/10.11 67/iovs.15-16583.

55. Vagge A, Nelson LB. Amblyopia update: new treatments. Curr Opin Ophthalmol. 2016 Sep:27(5):380-6. https://doi.org/10.1097/ICU. 0000000000000293.

56. Barboni MTS, Maneschg OA, Németh J, Nagy ZZ, Vidnyánszky Z, Bankó ÉM. Dichoptic spatial contrast sensitivity reflects binocular balance in Normal and Stereoanomalous subjects. Invest Ophthalmol Vis Sci. 2020 Sep 1;61(11): 23. https://doi.org/10.1167/iovs.61.11.23.

57. Midena E. Microperimetry and multimodal retinal imaging. New York: Springer Heidelberg; 2014. https://doi.org/10.1007/978-3-642-40300-2.

58. Amore FM, Paliotta S, Silvestri V, Piscopo P, Turco S, Reibaldi A. Biofeedback stimulation in patients with age-related macular degeneration: comparison between 2 different methods. Can J Ophthalmol J Can Ophtalmol. 2013; 48(5):431-7. https://doi.org/10.1016/j.jcjo.2013.07.013.

59. Nilsson UL, Frennesson C, Nilsson SE. Location and stability of a newly established eccentric retinal locus suitable for reading, achieved through training of patients with a dense central scotoma. Optom Vis Sci Off Publ Am Acad Optom. 1998;75(12):873-8. https://doi.org/10.1097/00006324-1 99812000-00009

60. Vingolo EM, Salvatore S, Cavarretta S. Low-vision rehabilitation by means of MP-1 biofeedback examination in patients with different macular diseases: a pilot study. Appl Psychophysiol Biofeedback. 2009 Jun;34(2):127-33. https:// doi.org/10.1007/s10484-009-9083-4.

61. Ueda-Consolvo T, Otsuka M, Hayashi Y, Ishida M, Hayashi A. Microperimetric biofeedback training improved visual acuity after successful macular hole surgery. J Ophthalmol. 2015;2015:572942.

\section{Publisher's Note}

Springer Nature remains neutral with regard to jurisdictional claims in published maps and institutional affiliations.

Ready to submit your research? Choose BMC and benefit from:

- fast, convenient online submission

- thorough peer review by experienced researchers in your field

- rapid publication on acceptance

- support for research data, including large and complex data types

- gold Open Access which fosters wider collaboration and increased citations

- maximum visibility for your research: over $100 \mathrm{M}$ website views per year

At BMC, research is always in progress.

Learn more biomedcentral.com/submissions 